\title{
Article \\ Molecule Dynamics Simulation of the Effect of Oxidative Aging on Properties of Nitrile Rubber
}

\author{
Jinsong Yang ${ }^{1}$ and Weitao Lou ${ }^{2, *(1)}$ \\ 1 School of Traffic and Transportation Engineering, Central South University, Changsha 410075, China; \\ yangjs@csu.edu.cn \\ 2 Graduate School of China Academy of Engineering Physics, Beijing 100193, China \\ * Correspondence: wtlou@gscaep.ac.cn; Tel.: +86-18810378827
}

Citation: Yang, J.; Lou, W. Molecule Dynamics Simulation of the Effect of Oxidative Aging on Properties of

Nitrile Rubber. Polymers 2022, 14, 226 https://doi.org/10.3390/

polym 14020226

Academic Editor: Emin Bayraktar

Received: 19 November 2021

Accepted: 4 January 2022

Published: 6 January 2022

Publisher's Note: MDPI stays neutral with regard to jurisdictional claims in published maps and institutional affiliations.

Copyright: (C) 2022 by the authors. Licensee MDPI, Basel, Switzerland. This article is an open access article distributed under the terms and conditions of the Creative Commons Attribution (CC BY) license (https:// creativecommons.org/licenses/by/ $4.0 /)$.

\begin{abstract}
The effects of oxidative aging on the static and dynamic properties of nitrile rubber at the molecular scale were investigated by molecular dynamics simulation. The aged nitrile rubber models were constructed by introducing hydroxyl groups and carbonyl groups into rubber molecular chains to mimic oxidative aging. The static and dynamic properties of the unaged and aged nitrile rubber under different conditions were evaluated by mean square displacement, self-diffusion coefficients, hydrogen bond, fractional free volume, radial distribution function, cohesive energy density and solubility parameter. The results show that the elevated temperature intensified significantly the mobility of rubber molecular chains and fractional free volume, while the compressive strain displayed the opposite effect resulting in packing and rearrangement of rubber chains. The introduction of hydroxyl groups and carbonyl groups enhanced the polarity, intermolecular interactions, the volume and rigidity of molecular chains, implying weaker mobility of molecular chains as compared to unaged models. The compressive strain and oxidative aging both decreased the fractional free volume, which inhibited gaseous and liquid diffusion into the rubber materials, and slowed down the oxidative aging rate. This study provides insights to better understand the effect of molecular changes due to oxidative aging on the structural and dynamic properties of rubber materials at the molecular level.
\end{abstract}

Keywords: nitrile rubber; oxidative aging; molecule dynamics simulation; hydroxyl groups; carbonyl groups

\section{Introduction}

Nitrile rubber (NBR) has been widely used as seals in sealing structures of hydraulic systems [1], due to its excellent oil resistance and mechanical properties. However, under practical service conditions, the rubber seals are often subjected to thermal cycles, oxygen, chemical media and mechanical stress leading inevitably to deterioration in chemical structures and mechanical properties [2-5]. With increasing service time, the rubber seals gradually lose elasticity which can lead to sealing failures and consequent leakage of gases and liquid [6-9].

The degradation mechanism of NBR under high temperature, chemical medium, radiation and stress has been widely studied for decades [10-14]. These studies indicate that the degradation mechanism of NBR includes physical reactions and chemical reactions, leading to deterioration in physical and mechanical properties [15]. The physical reactions consist of migration and volatilization of small molecular additives, creep and relaxation of rubber molecular chains $[16,17]$. The chemical reactions are made up of oxidation reactions such as crosslinking reactions, chain scission reactions and formation of oxidation products, which are mainly responsible for the degradation of NBR [14,18-20]. During the oxidative aging process, oxidation reactions occur leading to the formation of oxidation products such as hydroxyl groups, carbonyl groups and hyperoxide [21]. The formation of oxygencontaining groups enhances the polarity of rubber molecular chains, which seriously affects 
intermolecular interaction between rubber chains, energy distribution, and the mobility and flexibility of rubber chains, resulting in obvious changes in physical and chemical properties of NBR [22,23]. Moreover, the formation of polar groups in rubber chains may have positive or negative effects on diffusion behaviors of oxygen and other chemical species into the rubber materials, which may promote or inhibit degradation rates [24]. Many researchers focus on understanding the changes in rubber materials at the molecular level in an indirect or qualitative way, especially for oxidation products, associated with physical or mechanical properties by advanced experimental characterization methods, such as Fourier transform infrared spectroscopy (FTIR), X-ray photoelectron spectroscopy (XPS) and nuclear magnetic resonance spectroscopy (NMR) [25-27]. However, the molecular changes caused by oxidative aging on the static and dynamic characteristics of NBR at the molecular level still remain relatively unexplored.

In recent years, molecular dynamics (MD) simulation has been employed as an effective theoretical tool to comprehend quantitatively the structure-performance relationships of polymer materials at the molecular scale, especially in modification of polymers and diffusion of small molecules in polymers [28,29]. Although the molecular dynamics simulation methods were preliminarily applied to estimate the thermal oxidative aging mechanism of rubber materials [30-32], the chemical reactions such as oxidation products during the aging process are not fully considered by researchers. For example, Wang et al. [30] found that rubber at low compressive strain possesses high fractional free volume, molecular chain movement, and ozone permeability by molecular dynamics simulation. Zhi et al. [31] studied the heterogeneous oxidative aging and viscoelastic performance of rubber based on multi-scale simulation. The molecular dynamics simulation was used to investigate the permeability of oxygen in natural rubber. Hence, the influence of oxidative aging on the structural and dynamic properties of nitrile rubber requires further investigation.

In our previous studies, degradation behavior and the mechanism of rubber seals under actual service conditions such as elevated temperature, hydraulic oil and compressive strain were systematically investigated by accelerated tests [33,34]. It was found that the chemical reactions during the aging process, especially the oxidation products, presented significant effects on degradation in physical and mechanical properties of rubber seals. Thus, this work focuses on the influence of the oxidation products (hydroxyl group and carbonyl group) on the static and dynamic properties of NBR by using molecular dynamics simulation. Additionally, the aged NBR models were constructed on the basis of the oxidative rubber chains modified by oxidation products. After the molecular dynamics simulations, the influences of oxidative aging of rubber molecular chains on static and dynamic performances of NBR at different temperatures under uncompressed and compressed state at molecular scale were investigated by analyzing the mean square displacement (MSD), self-diffusion coefficients, hydrogen bonds, fractional free volume, radial distribution function and cohesive energy density.

\section{Simulation Models and Methods}

To study the effects of oxidative aging on nitrile rubber properties at the molecular level, unaged and aged nitrile rubber models were constructed by using the Forcite and Amorphous cell modules of Materials Studio 8.0 softwares, respectively. The COMPASS (condensed-phase optimized molecule potentials for atomistic simulation studies) force field was used for describing molecule interactions and intermolecular potential. The COMPASS force field is widely suitable for most common organics, small inorganic molecules and polymers, and can accurately predict the structural and thermophysical condensed phase properties of the related materials under a wide range of temperature and pressure conditions. The electrostatic and van der Waals forces were calculated by using the atom-based summation method. The Maxwell-Boltzmann profiles were used to set the initial velocities. Firstly, the repeating units of butadiene and acrylonitrile were constructed, respectively, shown in Figure 1. Then, the butadiene and acrylonitrile were copolymerized to form a nitrile rubber molecule chain with an acrylonitrile content of $35 \%$, containing 50 
repeating units. The chemical structures of the nitrile rubber molecule chain is shown in Figure 2. Secondly, an amorphous cell of the unaged NBR model was constructed with five molecule chains.

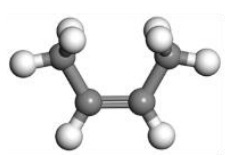

(a)

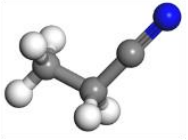

(b)

Figure 1. The repeating units of butadiene (a) and acrylonitrile (b).

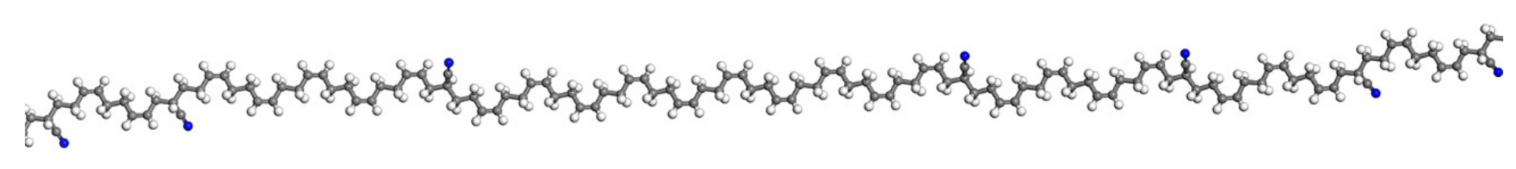

Figure 2. The chemical structure of the nitrile rubber molecule chain.

Previous studies indicated that the oxidation of rubber chains was mainly responsible for the performance degradation, accompanied by the formation of oxygen-containing functional groups [11,16,22,33-37]. The hydroxyl group and carbonyl group have been identified as major functional groups, which were formed during the oxidative aging process. The formation of these oxidation products can lead to changes in the molecular structure of the polymer matrix, which further results in degradation of physical and mechanical properties of rubber materials. Therefore, this study adopted the introduction of the hydroxyl groups and carbonyl groups in the molecule chains to modify the rubber chains in specified locations, representing oxidative aging effects. Figure 3 presents the aged rubber molecule chains modified by hydroxyl groups and carbonyl groups, respectively. Then, three types of aged NBR model were constructed, respectively, shown in Figure 4. In this study, the unaged NBR model is defined as "NBR". The aged NBR model modified by hydroxyl groups is defined as "OH-NBR". The aged NBR model modified by carbonyl groups is defined as "CO-NBR". The aged NBR model modified by hydroxyl groups and carbonyl groups together is defined as "OH-CO-NBR". The degree of polymerization values, DP, the total number of chains, $N_{\text {chain }}$, the total number of atoms, $N_{\text {atom }}$, and cell lengths, for the constructed models are given in Table 1. Although the methods employed in this work can be used to investigate the effects of hydroxyl groups and carbonyl groups on nitrile rubber properties, it is still impossible to directly simulate the real thermal-oxidative aging including oxidation products, crosslinking, and chain scission. Coupled effects of the oxidation products, crosslinking, and chain scission should be considered in further studies by introducing aging information.

In our previous publications [33,35], the effects of elevated temperature and compression deformation on physical and chemical properties of nitrile rubber were investigated. This study focuses on how the elevated temperature and compression deformation influence the molecular structure of the aged NBR. A 30\% compressive strain was respectively applied to the unaged and aged NBR models based on the actual compression state in the experimental study [35]. The compression deformation was applied along the Z-direction. Additionally, the X-direction and Y-direction were constrained to change shape and size of NBR models.

For the unaged and aged NBR models, the smart minimizer algorithm was applied to minimize the amorphous cells at $298.15 \mathrm{~K}$ for 1,000,000 steps, until a convergence value of $1.0 \times 10^{-5} \mathrm{Kcal} \mathrm{mol}^{-1} \AA^{-1}$ was reached. Then, the cells were annealed at $0.1 \mathrm{MPa}$ from $600 \mathrm{~K}$ to $300 \mathrm{k}$ for $200 \mathrm{ps}$ (picosecond). After that, $200 \mathrm{ps}$ of NPT (constant number of particles, pressure, and temperature) simulation was conducted at $300 \mathrm{~K}$ and $2 \mathrm{GPa}, 1 \mathrm{GPa}$, $0.5 \mathrm{GPa}$ to further relax the rubber chains, respectively. Then, $500 \mathrm{ps}$ of NVT (constant number of particles, volume, and temperature) simulation was carried out at $300 \mathrm{~K}$. Subsequently, 500 ps of NPT simulation was conducted at $300 \mathrm{~K}$ and $101 \mathrm{KPa}$ to obtain the 
stable structure. The simulated densities of the unaged NBR models were obtained and are given in Table 1 . The simulated densities agreed well with the experimental values $\left(\left|\rho_{M D}-\rho_{\text {Exp }}\right|<0.1 \mathrm{~g} / \mathrm{cm}^{3}\right)$, which proved the reliability of models [28]. The temperature and pressure were controlled by the Andersen thermostat [38] and Berendsen barostat [39], respectively. Finally, a 500 ps NVT product run was carried out at $101 \mathrm{kPa}$ and $298.15 \mathrm{~K}$ $\left(25^{\circ} \mathrm{C}\right), 343.15 \mathrm{~K}\left(70{ }^{\circ} \mathrm{C}\right), 363.15 \mathrm{~K}\left(90^{\circ} \mathrm{C}\right)$ and $383.15 \mathrm{~K}\left(110{ }^{\circ} \mathrm{C}\right)$, respectively, to obtain finally a stable structure and analyze the thermodynamic properties. These temperatures were selected on the basis of our previous experimental study [35]. Then, the radial distribution function (RDF), cohesive energy density (CED), the numbers and types of H-bonds, the fractional free volume (FFV), and radial distribution function (RDF) were estimated by further analysis of the equilibrated cells.

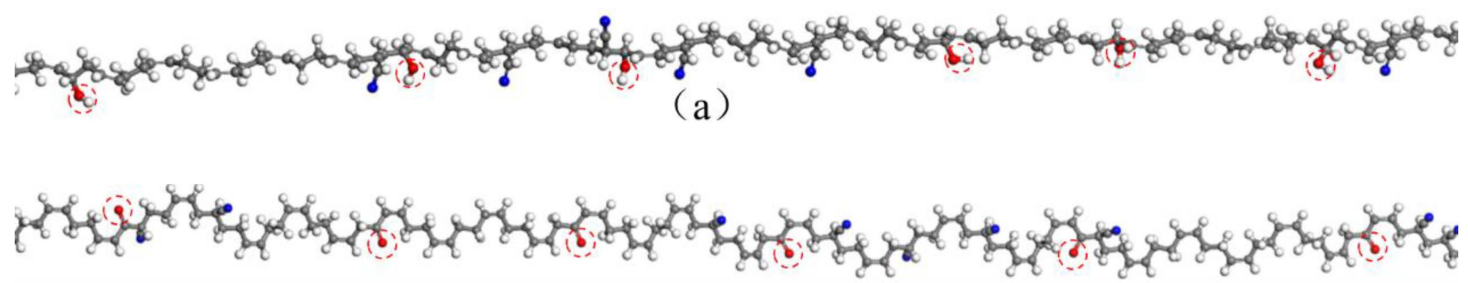

(b)

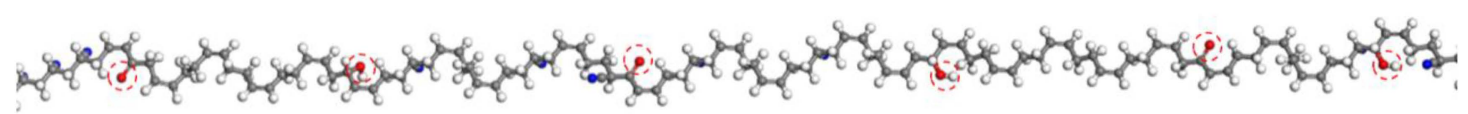

(c)

Figure 3. The aged rubber molecule chains modified by oxidation products: (a) hydroxyl groups; (b) carbonyl groups; (c) hydroxyl groups and carbonyl groups.

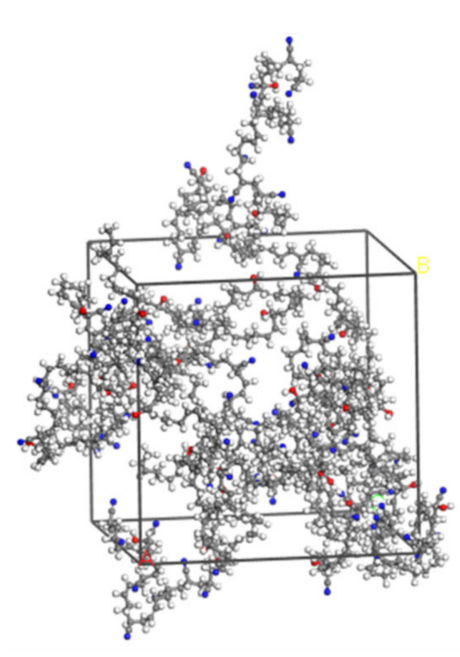

(a)

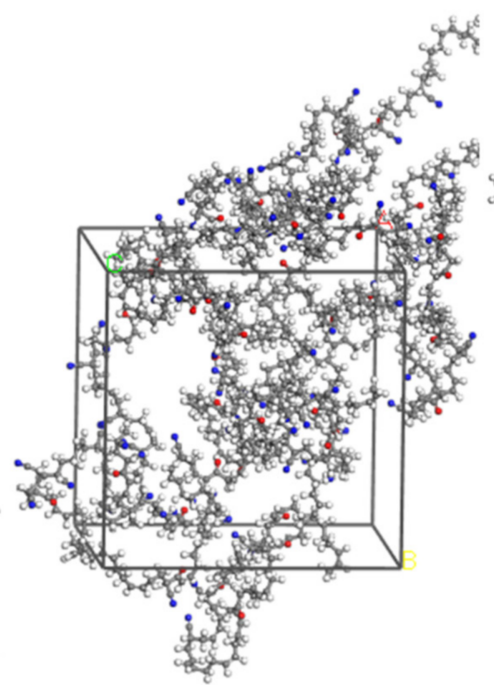

(b)

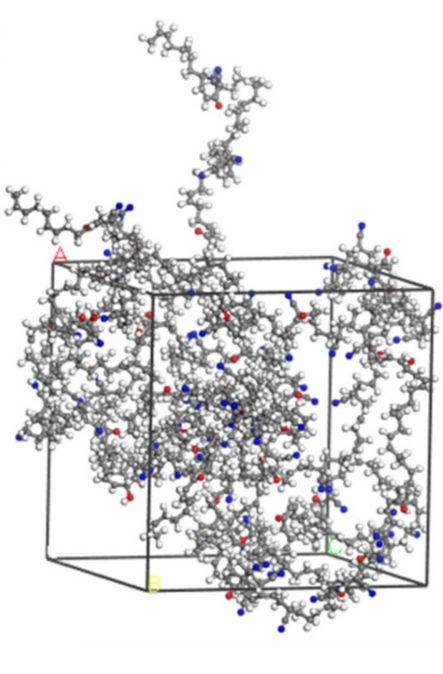

(c)

Figure 4. The aged nitrile rubber (NBR) model: (a) aged NBR model modified by hydroxyl groups (OH-NBR); (b) aged NBR model modified by carbonyl groups (CO-NBR); (c) aged NBR model modified by hydroxyl groups and carbonyl groups (OH-CO-NBR). 
Table 1. Details of the simulation models.

\begin{tabular}{ccccccc}
\hline Simulation Model & DP & $N_{\text {chain }}$ & $N_{\text {atom }}$ & $\rho_{M D}\left(\mathbf{g} / \mathrm{cm}^{3}\right)$ & $\rho_{\text {Exp }}\left(\mathrm{g} / \mathrm{cm}^{3}\right)$ & Cell Lengths $(\AA)$ \\
\hline NBR model & 50 & 5 & 2255 & 1.06 & 1.02 & 27.58 \\
OH-NBR model & 50 & 5 & 2295 & 1.09 & - & 27.71 \\
CO-NBR model & 50 & 5 & 2215 & 1.12 & - & 27.45 \\
OH-CO-NBR & 50 & 5 & 2255 & 1.11 & & 27.60 \\
model & & & & & \\
\hline
\end{tabular}

\section{Results and Discussion}

\subsection{Mean Square Displacement (MSD) and Self-Diffusion Coefficients}

To find out the effects of temperature, compression deformation and oxidative aging on the mobility of nitrile rubber molecule chains, the MSDs of rubber molecule chains in unaged and aged NBR models under different conditions were calculated, as shown in Figure 5. The results show that the MSDs of rubber chains increased with increasing simulation time, which is attributed to the motion of molecule chains. Besides, under the free state, the higher the temperature was, the faster the MSD increased, which indicates that high temperatures could significantly promote the mobility of chains [40-42]. Furthermore, the value of MSD under the compression state was obviously lower than that of the chains under the free state, even at higher temperature, implying that mobility of molecule chains was greatly restricted under the compression state. For the unaged and aged NBR models, a similar change tendency in MSD of the uncompressed and compressed samples was observed, and the value of MSD of the molecule chains in unaged NBR models was greater than that in aged NBR models. The MSD of the molecule chains in the OH-CO-NBR model presented the smallest value among the aged NBR models.

To further analyze the influence of hydroxyl groups and carbonyl groups on motion ability of rubber chains, the MSD was used to estimate self-diffusion coefficients by using the Einstein equation $[30,39,43,44]$, which is expressed as:

$$
D=\frac{1}{6 N} \lim _{t \rightarrow \infty} \frac{d}{d t} \sum_{i=1}^{N}\left\langle\left|r_{i}\left(t+t_{0}\right)-r_{i}\left(t_{0}\right)\right|^{2}\right\rangle
$$

where $N$ is the number of molecules, $D$ is the diffusion coefficient of rubber molecule chains, $r_{i}\left(t_{0}\right)$ is the displacement at $t_{0}, r_{i}\left(t+t_{0}\right)$ is the displacement at $t_{0}+t$, and

$$
M S D(t)=\frac{1}{N} \sum_{i=1}^{N}\left\langle\left|r_{i}\left(t+t_{0}\right)-r_{i}\left(t_{0}\right)\right|^{2}\right\rangle
$$

Table 2 shows the self-diffusion coefficients of rubber chains under different conditions. The results indicate that self-diffusion coefficients of unaged and aged NBR chains increased with temperature. Thus, the self-diffusion coefficients of rubber chains in different models conform to the order: NBR > OH-NBR > CO-NBR > OH-CO-NBR, which indicates that the mobility of the unaged rubber molecular chains was stronger than that of the aged rubber chains.

Table 2. The self-diffusion coefficients of unaged and aged NBR chains under different conditions.

\begin{tabular}{ccccc}
\hline \multirow{2}{*}{ Temperature/K } & \multicolumn{4}{c}{ Self-Diffusion Coefficient $\left.\mathbf{( 1 0}^{-\mathbf{7}} \mathbf{~ c m}^{\mathbf{2}} \mathbf{~ s}^{-\mathbf{1}}\right)$} \\
\cline { 2 - 5 } & NBR & OH-NBR & CO-NBR & OH-CO-NBR \\
\hline 298.15 & 1.83 & 1.41 & 1.09 & 0.94 \\
383.15 & 4.66 & 4.14 & 3.98 & 2.72 \\
\hline
\end{tabular}

Due to the addition of hydroxyl groups and carbonyl groups to the molecular chains, the energy and volume space required for the movement of the molecular chains is greater 
than that of the unaged rubber molecular chains, leading to the decrease in mobility. The decrease in MSD and self-diffusion coefficient of rubber molecular chains caused by oxidation aging were mainly due to the increase in volume and rigidity of rubber molecular chains.

Furthermore, the MSDs and self-diffusion coefficients of rubber molecular chains under the compression state displayed lower value compared to those in the uncompressed state. However, the MSDs of the compressed rubber molecular chains showed no obvious changes at low and high temperature, implying that the application of compressive strain resulted in the packing and rearrangement of molecular chains, and significantly limited the mobility of rubber molecular chains.
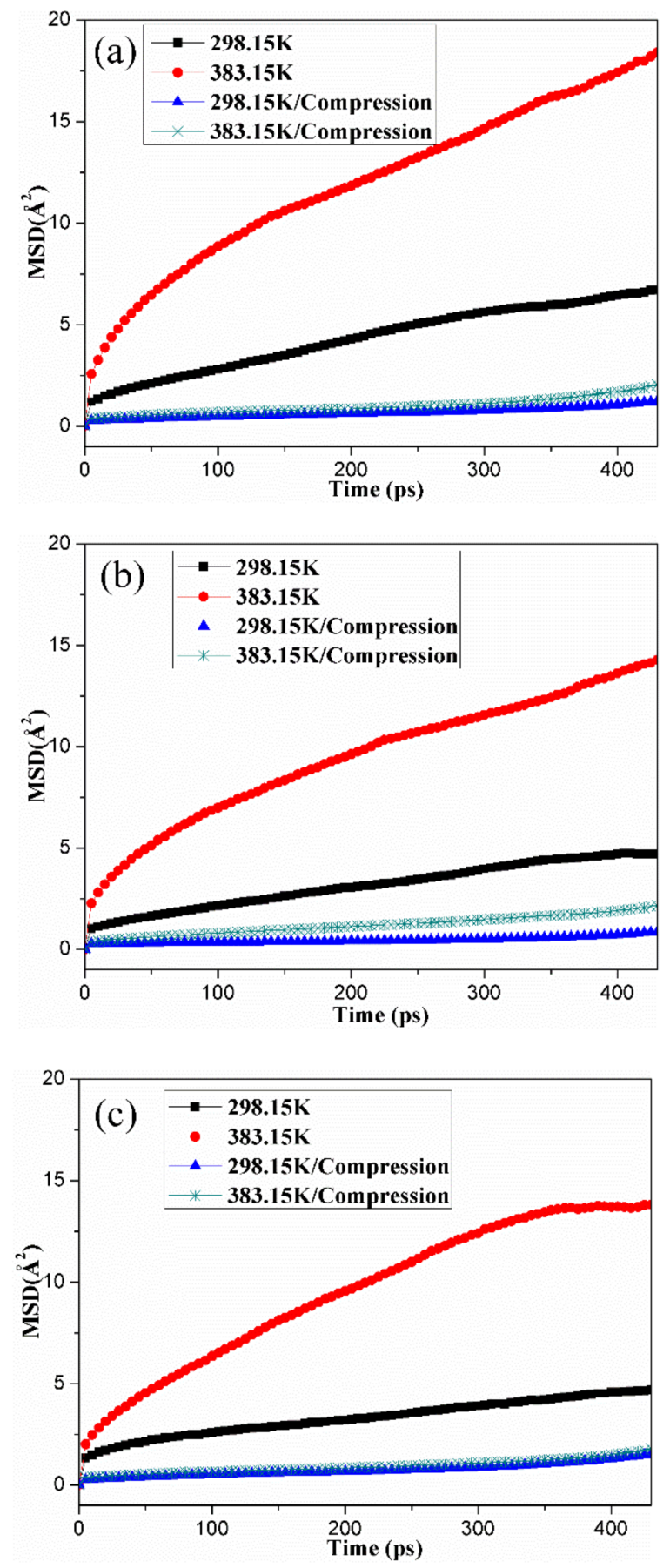

Figure 5. Cont. 


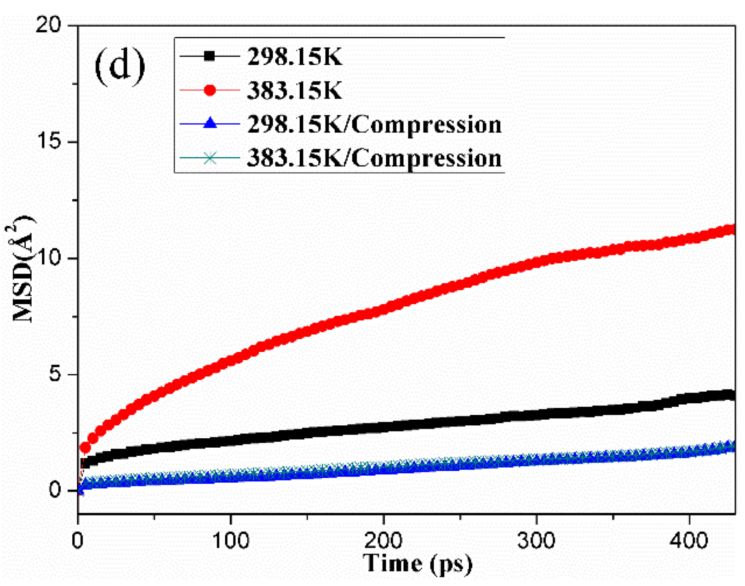

Figure 5. Changes in mean square displacement (MSD) of rubber molecule chains in unaged and aged NBR models under different conditions: (a) NBR; (b) OH-NBR; (c) CO-NBR; (d) OH-CO-NBR.

\subsection{Hydrogen Bond}

During the oxidative aging process, the oxidation functional groups that have strong polarity were formed in the rubber molecular chains. In this study, the hydroxyl groups and carbonyl groups were introduced in the rubber molecular chain to represent the oxidative aging of rubber molecular chain. The introduction of the polar groups contributed to the formation of strong polar interaction including non-bonded interaction and hydrogen bonds among the oxidized rubber chains, which affected the chain dynamics and structure properties of the rubber [29]. Therefore, it is necessary to analyze the influence of the type and number of hydrogen bonds in the rubber models.

Figure 6 shows the types of H-bond in the aged rubber model. The first H-bond ${ }_{(\mathrm{A})}$ or $\mathrm{O}-\mathrm{H} . . . \mathrm{N}$ (Figure 6a), was formed between the hydroxyl group and the nitrile group. The second $\mathrm{H}$-bond ${ }_{(\mathrm{B})}$ or $\mathrm{O}-\mathrm{H} . . . \mathrm{O}$ (Figure $6 \mathrm{~b}$ ), was formed between the hydroxyl group and the hydroxyl group. The third H-bond ${ }_{(\mathrm{C})}$ or $\mathrm{O}-\mathrm{H} . . . \mathrm{O}$ (Figure $6 \mathrm{c}$ ), was formed between the hydroxyl group and the carbonyl group. By further analysis, it was found that the H-bonds occurred only in the OH-NBR model and OH-CO-NBR model, shown in Figures 7 and 8. Meanwhile, Table 3 shows the types and number of $\mathrm{H}$-bonds in aged NBR models. The results show that the number of H-bonds (A) in the uncompressed OH-NBR model and $\mathrm{OH}-\mathrm{CO}-\mathrm{NBR}$ model decreased with increasing temperature, but presented the opposite trend in the compressed state. Additionally, the number of H-bonds ${ }_{(B)}$ in the OH-NBR model and OH-CO-NBR model displayed no obvious changes with temperature. The H-bond ${ }_{(\mathrm{C})}$ only existed in OH-CO-NBR model. Moreover, the number of H-bonds ${ }_{(\mathrm{C})}$ in the uncompressed $\mathrm{OH}-\mathrm{CO}-\mathrm{NBR}$ model showed a slight increase with temperature. These phenomena illustrate that the elevated temperature destroyed the $\mathrm{H}$-bond (A) and $\mathrm{H}$-bond (B) in the uncompressed state. This is mainly because the elevated temperature promoted the mobility of molecular chains and increased the chain space, until the intermolecular distance could no longer meet the conditions to form the hydrogen bond. However, the high temperature promoted the formation of the H-bond (A) under the compression state due to the sufficient energy supplied by elevated temperature. However, at $298.15 \mathrm{~K}$, the number of $\mathrm{H}$-bonds (A) in the compressed state was less than that in the uncompressed state. The results demonstrate that compressive strain destroyed the hydrogen bonds and limited the formation of new hydrogen bond, due to the lower mobility of rubber molecular chains under the coupled effect of lower temperature and compressive strain, which was explained by the results of the MSD and self-diffusion coefficient of rubber molecular chains. However, at $383.15 \mathrm{~K}$, the changes in the number of H-bonds (A) showed an adverse trend, implying that the coupled influence of compressive strain and elevated temperature facilitates the formation of H-bond (A). Nevertheless, the results of the MSD and self-diffusion coefficient of rubber molecular chains at $383.15 \mathrm{~K}$ in the compressed state 
displayed a lower mobility of rubber molecular chains. Thus, the increase in the number of H-bonds (A) was attributed to the fast motion of local segments and side groups caused by the high temperature. The formation of $\mathrm{H}$-bonds strengthened the interaction force between molecular chains, and further restricted the movement of rubber molecular chains.

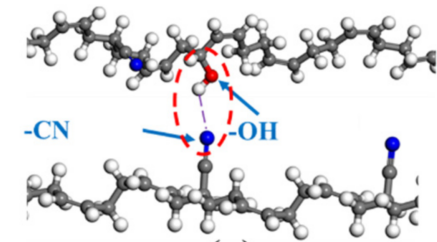

(a)

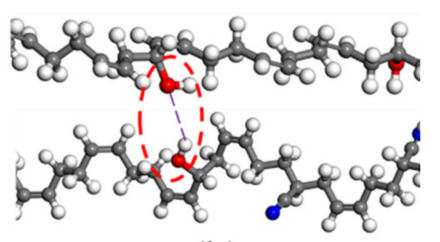

(b)

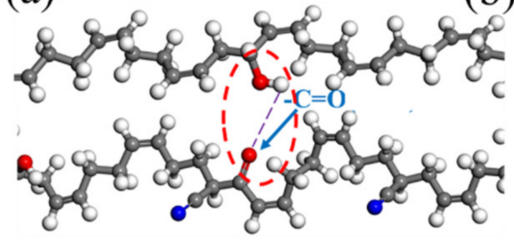

(c)

Figure 6. The types of $\mathrm{H}$-bond in the aged rubber model: (a) H-bond ${ }_{(\mathrm{A})}$ or $\mathrm{O}-\mathrm{H} . . . \mathrm{N}$; (b) H-bond (B) or $\mathrm{O}-\mathrm{H} \ldots \mathrm{O}(-\mathrm{OH})$; (c) H-bond $(\mathrm{C})$ or $\mathrm{O}-\mathrm{H} . . . \mathrm{O}(-\mathrm{CO})$.

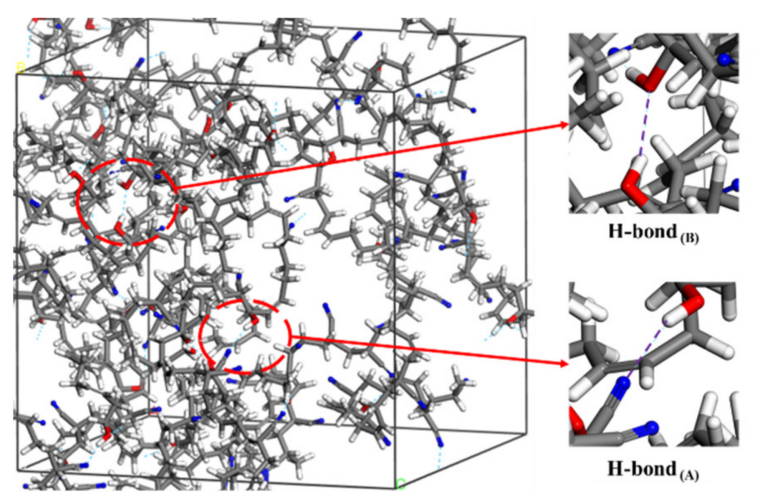

Figure 7. Two types of H-bond in OH-NBR model.

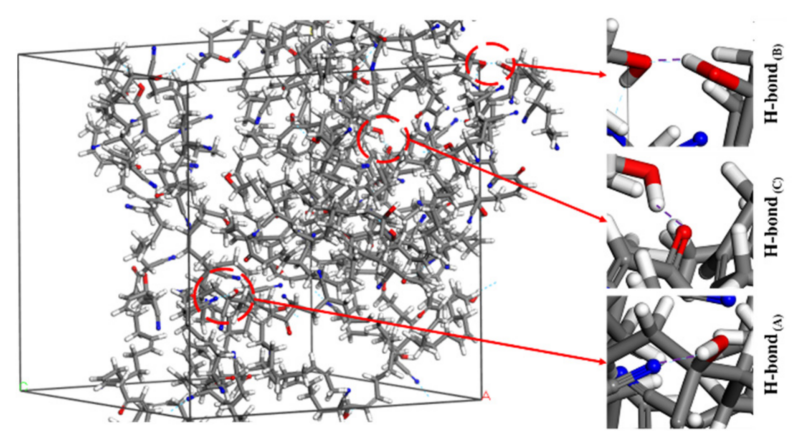

Figure 8. Three types of H-bond in OH-CO-NBR model. 
Table 3. The types and number of H-bonds in aged NBR models.

\begin{tabular}{|c|c|c|c|c|c|c|c|c|}
\hline \multirow{3}{*}{ Type of Hydrogen Bond } & \multicolumn{4}{|c|}{ OH-NBR } & \multicolumn{4}{|c|}{ OH-CO-NBR } \\
\hline & \multicolumn{2}{|c|}{ Uncompresssed } & \multicolumn{2}{|c|}{ Compressed } & \multicolumn{2}{|c|}{ Uncompresssed } & \multicolumn{2}{|c|}{ Compressed } \\
\hline & $298.15 \mathrm{~K}$ & $383.15 \mathrm{~K}$ & $298.15 \mathrm{~K}$ & $383.15 \mathrm{~K}$ & $298.15 \mathrm{~K}$ & $383.15 \mathrm{~K}$ & $298.15 \mathrm{~K}$ & $383.15 \mathrm{~K}$ \\
\hline A & 26 & 20 & 22 & 26 & 18 & 13 & 14 & 16 \\
\hline $\mathrm{B}$ & 6 & 4 & 5 & 5 & 2 & 2 & 2 & 2 \\
\hline $\mathrm{C}$ & 0 & 0 & 0 & 0 & 2 & 5 & 2 & 2 \\
\hline
\end{tabular}

\subsection{Fractional Free Volume (FFV)}

Fractional free volume (FFV) can be defined as the fraction of the volume not occupied by the polymer, which is often used to estimate the available space for free movement of rubber chain and the efficiency of rubber chain packing. The FFV can be calculated by the following equation:

$$
F F V=1-\frac{V_{0}}{V_{S}}
$$

where the occupied volume $V_{0}=1.3 V_{\mathrm{w}}, V_{\mathrm{w}}$ is the van der Waals's volume, and vs. is the specific volume.

Figure 9 shows the Connolly volume morphology in the uncompressed and compressed states. The blue and gray regions represent the free volume and the occupied volume, respectively. Figure 10 presents the FFV of the unaged and aged NBR models in the uncompressed and compressed states. The FFV of rubber models all increased with increase in temperature, and the free volume fraction of rubber in the uncompressed state presented a bigger value than that in the compressed state. Furthermore, the FFV of the unaged NBR models was greater than that of the aged NBR models. Additionally, the FFV value of the aged models conforms to the order: $\mathrm{FFV}_{\mathrm{OH}-\mathrm{NBR}}>\mathrm{FFV}_{\mathrm{CO}-\mathrm{NBR}}>\mathrm{FFV}_{\mathrm{OH}-\mathrm{CO}-\mathrm{NBR}}$.

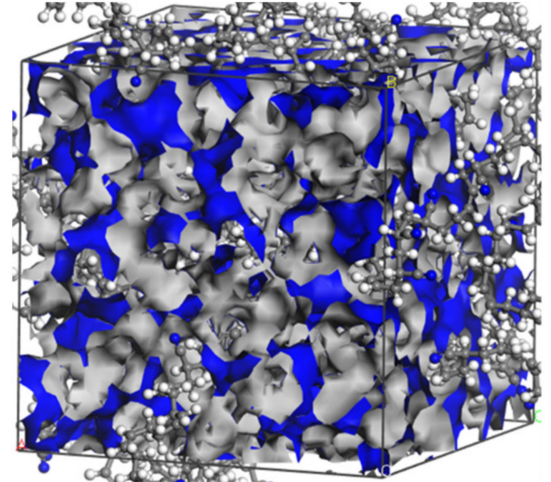

(a) $0 \%$

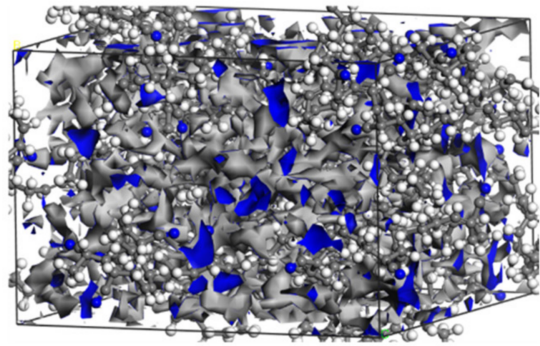

(b) $30 \%$

Figure 9. The Connolly volume morphology of NBR model in the uncompressed (a) and compressed (b) states, respectively (the blue and gray regions represent the free volume and the occupied volume, respectively).

The volume of rubber models is mainly composed of the volume of the rubber chain and the free volume caused by thermal movement of rubber chain. With increase of temperature, the conformational entropy increased and chain segments motioned significantly, leading to an increase of FFV [30]. Additionally, the application of compressive strain limited the thermal movement of the rubber molecular chains, resulting in efficient molecular packing and a decrease of FFV. When the hydroxyl groups and carbonyl groups were introduced in the rubber molecular chains, these polar groups contributed to the formation of strong polar interactions among molecule chains. Moreover, the introduction of the polar groups increased the rigidity of rubber chains, and promoted tight packing of rubber 
molecular chains, which led to decrease in FFV. These results indicate that the compressive strain and oxidation functional groups both have a negative influence on the changes of FFV.
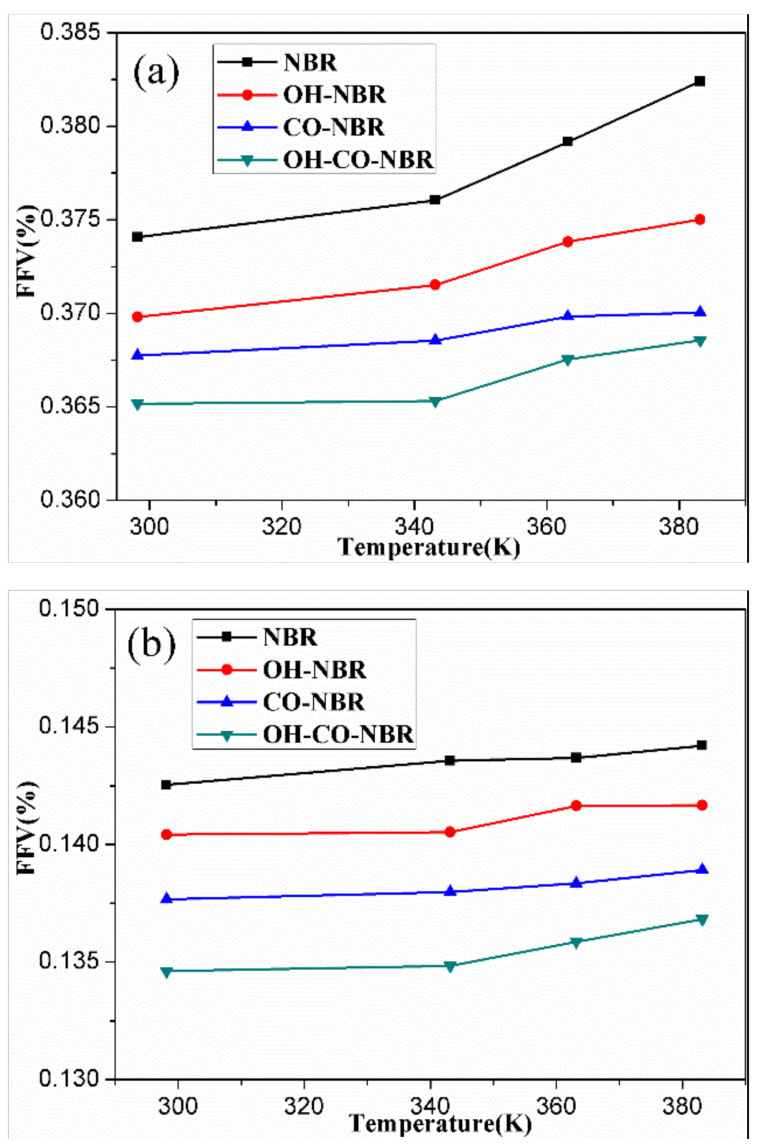

Figure 10. The fractional free volume (FFV) of the unaged and aged NBR models in the uncompressed (a) and compressed (b) state.

\subsection{Radial Distribution Function (RDF)}

The radial distribution function (RDF) is defined as the probability of finding another atom at a distance from a specific atom, which can be used to estimate the interactions between the components and static properties of a rubber model. The RDF can be calculated by the following equation [29]:

$$
g(r)=\frac{1}{\rho_{B}} \frac{1}{N_{A}} \sum_{i}^{N_{B}} \sum_{j}^{N_{A}} \frac{\delta\left(r_{i j}-r\right)}{4 \pi r^{2}}
$$

where $r$ is the distance, $r_{i j}$ is the coordinate of the atom; $N_{A}$ and $N_{B}$ are the numbers of atom $\mathrm{A}$ and $\mathrm{B} ; \rho_{B}$ is the average density of the atom $\mathrm{B}$ at a given distance $r$ as a center of atom $\mathrm{A}$.

Figures 11-15 show the RDFs of carbon atoms $(C-C)$ in the unaged and aged NBR models under different conditions, respectively. The peaks at $1.10 \AA, 1.33 \AA$ and $1.53 \AA$ can be assigned to the bond length of $\mathrm{C}-\mathrm{H}, \mathrm{C}=\mathrm{C}$ and $\mathrm{C}-\mathrm{C}$, respectively $[31,39]$. The peak at $0.94 \AA$ belongs to the bond length of $\mathrm{O}-\mathrm{H}$. Besides, when the distance is beyond $3.5 \AA$, no obvious peaks appear, implying that the models present long range disorder and the models are consistent with amorphous structure, which confirms the effectiveness of the constructed models. Additionally, the peak value of RDF decreased slightly with increase of temperature, indicating that the elevated temperature resulted in stronger mobility, an increase in flexibility and a decrease in the order of rubber chains. Furthermore, the peak value of RDF in the compressed state displayed a smaller value than that in the 
uncompressed state, implying that the compressive strain led to an increase in disorder and chain stacking. When the hydroxyl groups and carbonyl groups were used to modify the rubber molecular chains, it was found that the peak value of RDF showed a slight decrease in aged rubber models. This is mainly because the introduction of hydroxyl groups and carbonyl groups increased the intermolecular forces between molecular chains, and decreased the segment motion and flexibility of molecular chains.
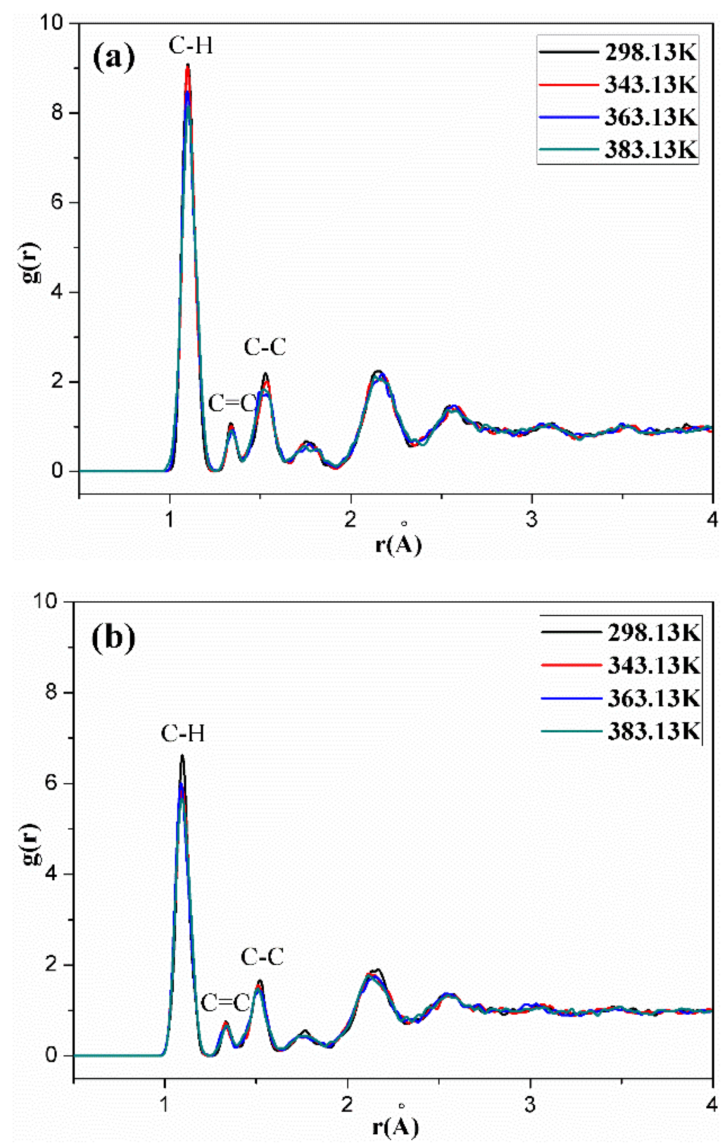

Figure 11. The molecule-molecule radial distribution functions (RDFs) of carbon atoms $(C-C)$ in the NBR model in the uncompressed (a) and compressed (b) states.

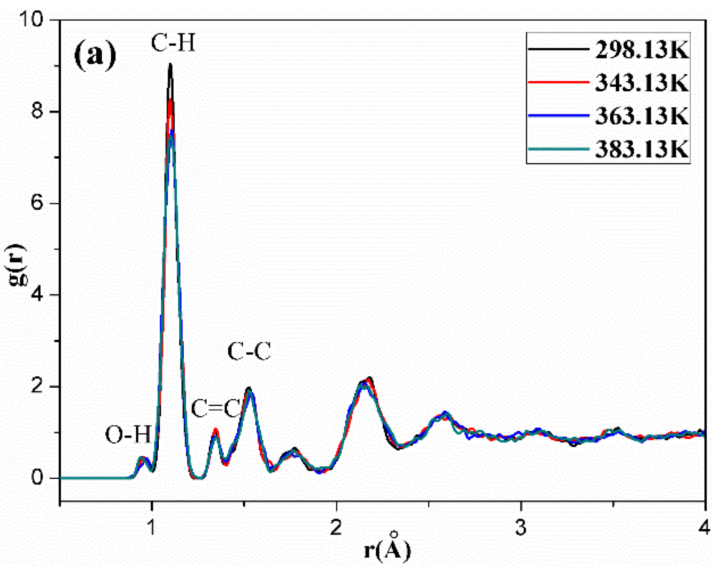

Figure 12. Cont. 


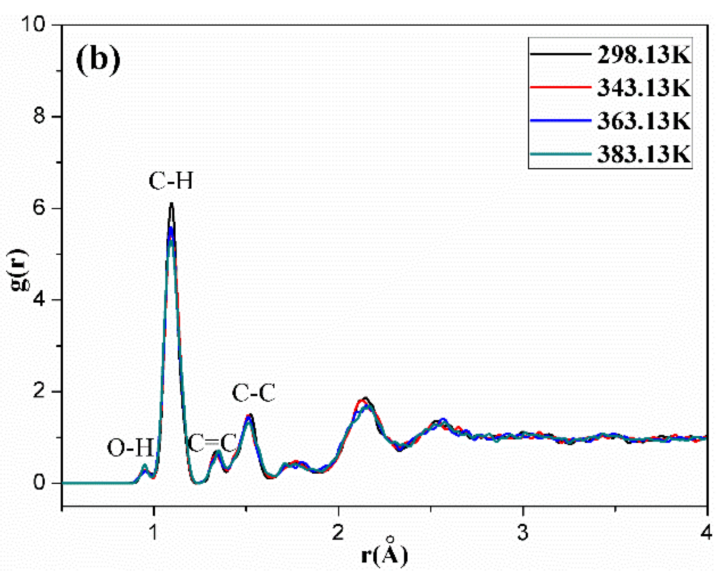

Figure 12. The radial distribution functions (RDFs) of carbon atoms $(C-C)$ in the $O H-N B R$ model in the uncompressed (a) and compressed (b) states.
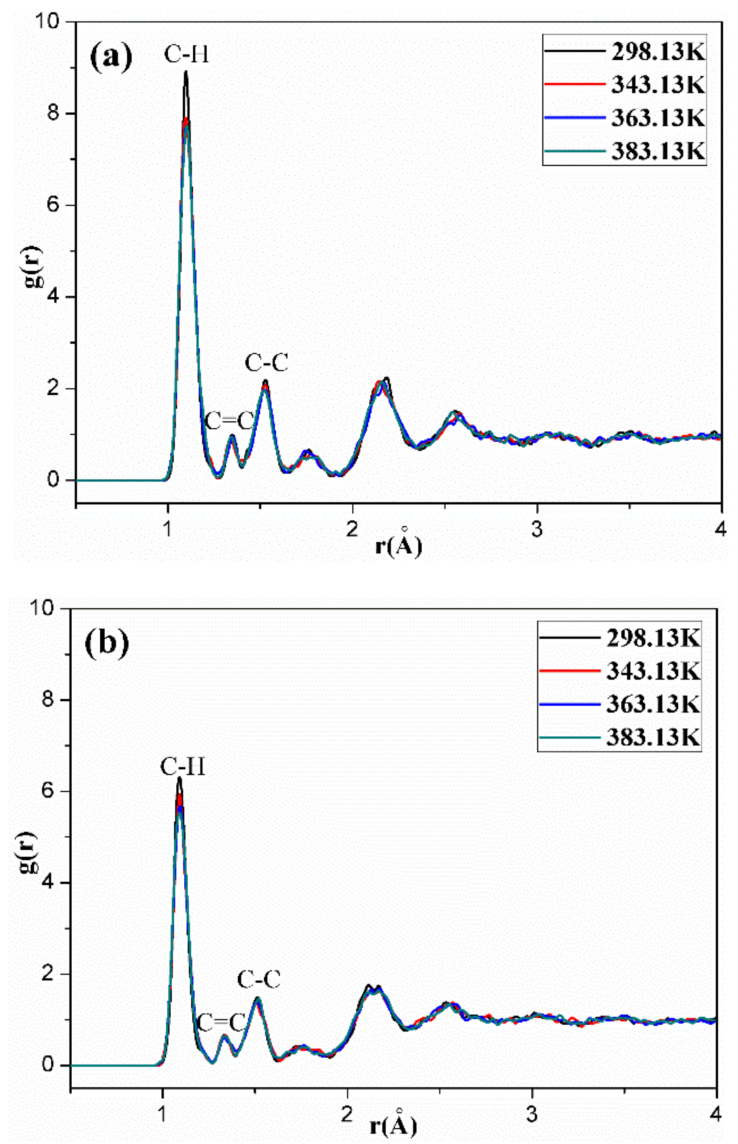

Figure 13. The radial distribution functions (RDFs) of carbon atoms $(\mathrm{C}-\mathrm{C})$ in the CO-NBR model in the uncompressed (a) and compressed (b) states. 

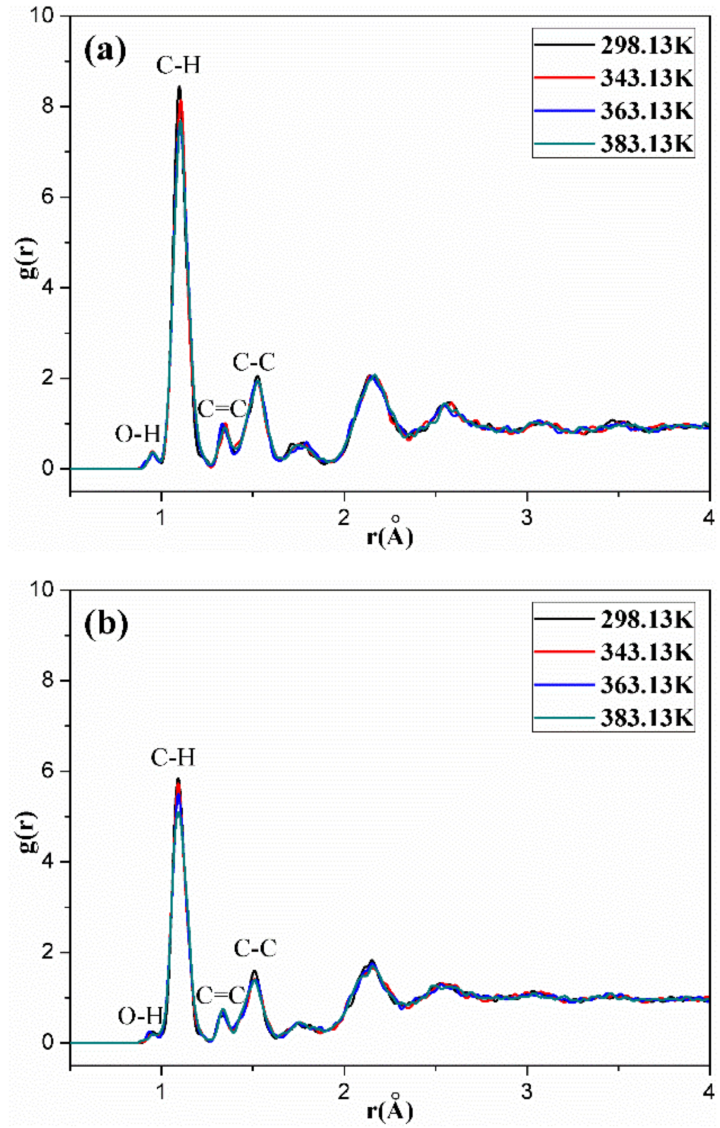

Figure 14. The radial distribution functions (RDFs) of carbon atoms $(\mathrm{C}-\mathrm{C})$ in the OH-CO-NBR model in the uncompressed (a) and compressed (b) states.

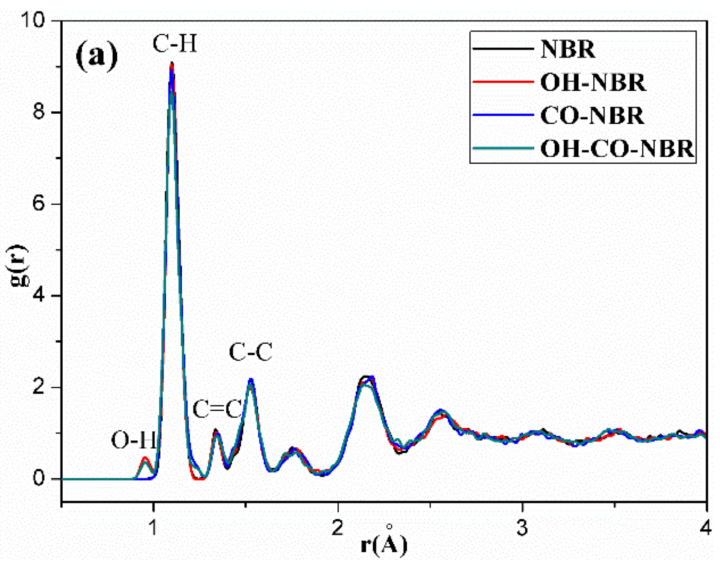

Figure 15. Cont. 


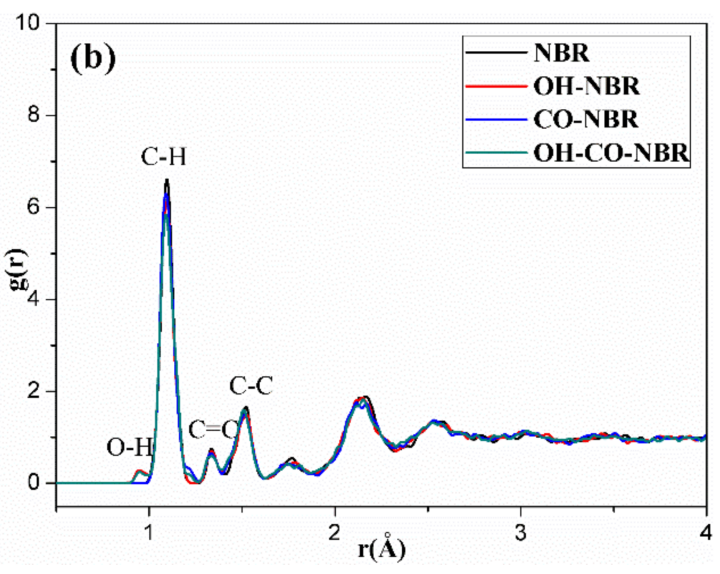

Figure 15. The radial distribution functions (RDFs) of carbon atoms $(C-C)$ in the unaged and aged NBR model at $298.15 \mathrm{~K}$ in the uncompressed (a) and compressed (b) states.

\subsection{Cohesive Energy Density (CED) and Solubility Parameter $(\delta)$}

As defined by Hildebrand and Scott [45], cohesive energy density (CED) can be used to characterize the strength of attractive interactions representing intermolecular force including van der Waals force and Coulomb force, and the solubility parameter $(\delta)$ is simply the square root of the cohesive energy density (CED).

Table 4 shows the cohesive energy density and solubility parameters of different oxidative aging models. The results indicate that the CED and solubility parameters of the aged model were higher than those of the unaged model, due to the stronger intermolecular interaction among molecular chains caused by the polar groups. Moreover, the CED and solubility parameters of the aged models conform to the order: OH-CO-NBR $>$ OH-NBR $>$ CO-NBR, due to the effect of strong polar interaction and the hydrogen bonds. When compressive strain was applied to the unaged and aged models, it was found that the CED of the rubber model in the compressed state was lower than that of the rubber model in the uncompressed state, implying that compressive strain weakened the intermolecular force. This is mainly because the compressive strain destroyed the strong polar interaction and hydrogen bond among the rubber molecular chains.

Table 4. The cohesive energy density (CED) and solubility parameters of the unaged and aged NBR models.

\begin{tabular}{cccccc}
\hline Compression Set & Rubber Model & NBR & OH-NBR & CO-NBR & OH-CO-NBR \\
\hline \multirow{2}{*}{0} & $\mathrm{CED}\left(10^{8} \mathrm{~J} / \mathrm{cm}^{-3}\right)$ & 3.07 & 3.52 & 3.38 & 3.62 \\
& $\delta\left(\mathrm{J} / \mathrm{cm}^{-3}\right)^{1 / 2}$ & 17.51 & 18.77 & 18.41 & 19.02 \\
\multirow{2}{*}{$30 \%$} & $\mathrm{CED}\left(10^{8} \mathrm{~J} / \mathrm{cm}^{-3}\right)$ & 2.41 & 2.96 & 2.67 & 2.84 \\
& $\delta\left(\mathrm{J} / \mathrm{cm}^{-3}\right)^{1 / 2}$ & 15.53 & 17.20 & 16.35 & 16.85 \\
\hline
\end{tabular}

\section{Conclusions}

Aged NBR models were constructed by the introduction of hydroxyl groups and carbonyl groups in rubber molecular chains to investigate the influence of oxidative aging on the static and dynamic characteristics of nitrile rubber using MD simulation. The following conclusions can be drawn:

1. The MSD and RDF results show that elevated temperature promoted significantly the mobility of rubber chains, while the compressive strain displayed the opposite effect. The introduction of hydroxyl groups and carbonyl groups weakened the mobility of rubber molecular chains due to increases in polarity, intermolecular force, volume and rigidity of rubber chains.

2. Hydrogen bonding analysis results demonstrate that the interaction forces including the strong polar interaction and hydrogen bond among chains were intensified due to 
the introduction of hydroxyl groups and carbonyl groups. In the uncompressed state, high temperature destroyed the formation of $\mathrm{H}$-bonds (A) or O-H...N. The increase in cohesive energy density of the aged NBR models also reflected the formation of interaction forces.

3. The fractional free volume results indicate that the fractional free volume increased with increasing temperature, whereas the compressive strain and the introduction of oxidation functional groups decreased the fractional free volume.

Author Contributions: Conceptualization, Data curation, Validation, Visualization, and Formal analysis, J.Y. and W.L; methodology, investigation, writing-original draf, writing-review and editing, W.L. All authors have read and agreed to the published version of the manuscript.

Funding: This research was funded by the National Key R\&D Program of China (Grant number 2020YFA0710904-04), the National Natural Science Foundation of China (grant number 51805548), and the Natural Science Foundation of Hunan Province China (grant number 2020JJ5756).

Institutional Review Board Statement: Not applicable.

Informed Consent Statement: Not applicable.

Data Availability Statement: Data is contained within the article.

Conflicts of Interest: The authors declare no conflict of interest.

\section{References}

1. Pazur, R.J.; Cormier, J.G.; Korhan-Taymaz, K. Service life determination of nitrile O-rings in hydraulic fluid. Rubber. Chem. Technol. 2014, 87, 239-249. [CrossRef]

2. Akhlaghi, S.; Gedde, U.W.; Hedenqvist, M.S.; Braña, M.T.C.; Bellander, M. Deterioration of automotive rubbers in liquid biofuels: A review. Renew. Sust. Energy Rev. 2015, 43, 1238-1248. [CrossRef]

3. Zhao, J.; Yang, R.; Iervolino, R.; Barbera, S. Changes of chemical structure and mechanical property levels during thermo-oxidative aging of NBR. Rubber. Chem. Technol. Rubber. Chem. Technol. 2013, 86, 591-603. [CrossRef]

4. Alcock, B.; Jørgensen, J.K. The mechanical properties of a model hydrogenated nitrile butadiene rubber (HNBR) following simulated sweet oil exposure at elevated temperature and pressure. Polym. Test. 2015, 46, 50-58. [CrossRef]

5. Han, R.; Wu, Y.; Quan, X.; Niu, K. Effects of crosslinking densities on mechanical properties of nitrile rubber composites in thermal oxidative aging environment. J. Appl. Polym. Sci. 2020, 137, e49076. [CrossRef]

6. Yamabe, J.; Koga, A.; Nishimura, S. Failure behavior of rubber O-ring under cyclic exposure to high-pressure hydrogen gas. Eng. Fail. Anal. 2013, 35, 193-205. [CrossRef]

7. Buckley, G.S.; Roland, C.M. Influence of liquid media on lifetime predictions of nitrile rubber. J. Appl. Polym. Sci. 2014, 131, 2928-2935. [CrossRef]

8. Pan, L.; Tan, J.; Han, X.; Li, P.; Zhang, W. Effects of elevated temperature and crude oil on the properties of a hydrogenated nitrile butadiene rubber elastomer. J. Appl. Polym. Sci. 2016, 133, 44012. [CrossRef]

9. Ahmed, F.S.; Shafy, M.; Abd El-Megeed, A.A.; Hegazi, E.M. The effect of $\gamma$-irradiation on acrylonitrile-butadiene rubber NBR seal materials with different antioxidants. Mater. Design 2012, 36, 823-828. [CrossRef]

10. Guo, F.; Jia, X.; Lv, M.; Wang, L.; Salant, R.F.; Wang, Y. The effect of aging in oil on the performance of a radial lip seal. Tribol. Int. 2014, 78, 187-194. [CrossRef]

11. Liu, J.; Li, X.; Xu, L.; Zhang, P. Investigation of aging behavior and mechanism of nitrile-butadiene rubber (NBR) in the accelerated thermal aging environment. Polym. Test. 2016, 54, 59-66. [CrossRef]

12. Celina, M.; Wise, J.; Ottesen, D.K.; Gillen, K.T.; Clough, R.L. Oxidation profiles of thermally aged nitrile rubber. Polym. Degrad. Stabil. 1998, 60, 493-504. [CrossRef]

13. Bhattacharjee, S.; Bhowmick, A.K.; Avasthi, B.N. Degradation of hydrogenated nitrile rubber. Polym. Degrad. Stabil. 1991, 31, 71-87. [CrossRef]

14. Celina, M.; Linde, E.; Brunson, D.; Quintana, A.; Giron, N. Overview of accelerated aging and polymer degradation kinetics for combined radiation-thermal environments. Polym. Degrad. Stabil. 2019, 166, 353-378. [CrossRef]

15. Zhao, J.; Yang, R.; Iervolino, R.; Barbera, S. Investigation of crosslinking in the thermo oxidative aging of nitrile-butadiene rubber. J. Appl. Polym. Sci. 2014, 132, 41319. [CrossRef]

16. Zhao, J.; Yang, R.; Iervolino, R.; Vorst, B.V.D.; Barbera, S. The effect of thermo-oxidation on the continuous stress relaxation behavior of nitrile rubber. Polym. Degrad. Stabil. 2015, 115, 32-37. [CrossRef]

17. Wang, Q.; Wang, F.; Cheng, K. Effect of crosslink density on some properties of electron beam-irradiated styrene-butadiene rubber. Radiat. Phys. Chem. 2009, 78, 1001-1005. [CrossRef] 
18. Zheng, W.; Zhao, X.; Li, Q.; Chan, T.W.; Zhang, L.; Wu, S. Compressive stress relaxation modeling of butadiene rubber under thermos-oxidative aging. J. Appl. Polym. Sci. 2017, 134, 44630. [CrossRef]

19. Hou, F.; Song, Y.; Zheng, Q. Payne effect of thermo-oxidatively aged isoprene rubber vulcanizates. Polymer 2020, 195, 12243. [CrossRef]

20. Hamid, M.; Vahid, M.; Emad, P.; Roozbeh, D. Understanding decay functions and their contribution in modeling of thermalinduced aging of cross-linked polymers. Polym. Degrad. Stabil. 2020, 175, 109108.

21. Kömmling, A.; Jaunich, M.; Wolff, D. Effects of heterogeneous aging in compressed HNBR and EPDM O-ring seals. Polym. Degrad. Stabil. 2016, 126, 39-46. [CrossRef]

22. Zeng, D.; He, Q.; Li, T.; Hu, J.; Shi, T.; Zhang, Z.; Yu, Z.; Liu, R. Corrosion mechanism of hydrogenated nitrile butadiene rubber O-ring under simulated wellbore conditions. Corros. Sci. 2016, 107, 145-154. [CrossRef]

23. Delor-Jestin, F.; Barrois-Oudin, N.; Cardinet, C.; Lacoste, J.; Lemaire, J. Thermal ageing of acrylonitrile-butadiene copolymer. Polym. Degrad. Stabil. 2000, 70, 1-4. [CrossRef]

24. Coronado, M.; Montero, G.; Valdez, B.; Stoytcheva, M.; Eliezer, A.; García, C.; Campbell, H.; Pérez, A. Degradation of nitrile rubber fuel hose by biodiesel use. Energy 2014, 68, 364-369. [CrossRef]

25. Akhlaghi, S.; Hedenqvist, M.S.; Conde Braña, M.T.; Bellander, M.; Gedde, U.W. Deterioration of acrylonitrile butadiene rubber in rapeseed biodiesel. Polym. Degrad. Stabil. 2015, 111, 211-222. [CrossRef]

26. Zhao, J.; Liu, Y.; Yang, R. Volatile components changes during thermal aging of nitrile rubber by flash evaporation of Py-GC/MS J. Anal. Appl. Pyrol. 2014, 113, 193-201. [CrossRef]

27. Yang, R.; Zhao, J.; Liu, Y. Oxidative degradation products analysis of polymer materials by pyrolysis gas chromatography-mass spectrometry. Polym. Degrad. Stabil. 2013, 98, 2466-2472. [CrossRef]

28. Song, M.; Zhao, X.; Chan, T.; Zhang, L.; Wu, S. Microstructure and Dynamic Properties Analyses of Hindered Phenol AO80/Nitrile Butadiene Rubber/Poly(vinyl chloride): A Molecular Simulation and Experimental Study. Macromol. Theory Simul. 2015, 24, 41-51. [CrossRef]

29. Zhao, X.; Zhang, G.; Lu, F.; Zhang, L.; Wu, S. Molecular-level insight of hindered phenol AO-70/nitrile-butadiene rubber damping composites through a combination of a molecular dynamics simulation and experimental method. RSC Adv. 2016, 6, 85994 [CrossRef]

30. Wang, X.-J.; Zhao, X.-Y.; Li, Q.-G.; Chan, T.W.; Wu, S.-Z. Artificial Neural Network Modeling and Mechanism Study for Relaxation of Deformed Rubber. Ind. Eng. Chem. Res. 2016, 55, 4059-4070. [CrossRef]

31. Wang, W.; Tanaka, Y.; Takada, T.; Iwata, S.; Uehara, H.; Li, S. Influence of oxidation on the dynamics in amorphous ethylenepropylene-diene-monomer copolymer: A molecular dynamics simulation. Polym. Degrad. Stabil. 2018, 147, 187-196. [CrossRef]

32. Liu, Q.; Huang, W.; Liu, B.; Wang, P.C.; Chen, H.B. Gamma Radiation Chemistry of Polydimethylsiloxane Foam in RadiationThermal Environments: Experiments and Simulations. ACS Appl. Mater. Interfaces 2021, 13, 41287-41302. [CrossRef]

33. Lou, W.; Zhang, W.; Liu, X.; Dai, W.; Xu, D. Degradation of hydrogenated nitrile rubber (HNBR) O-rings exposed to simulated servo system conditions. Polym. Degrad. Stabil. 2017, 144, 464-472. [CrossRef]

34. Lou, W.T.; Zhang, W.F.; Wang, H.X.; Jin, T.Z.; Liu, X.R. Influence of hydraulic oil on degradation behavior of nitrile rubber O-rings at elevated temperature. Eng. Fail. Anal. 2018, 92,1-11. [CrossRef]

35. Lou, W.; Zhang, W.; Jin, T.; Liu, X.; Wang, H. Stress-thermal oxidative aging behavior of hydrogenated nitrile rubber seals. J. Appl. Polym. Sci. 2018, 136, 47014. [CrossRef]

36. Morrell, P.R.; Patel, M.; Skinner, A.R. Accelerated thermal ageing studies on nitrile rubber O.-rings. Polym. Test. 2003, 22, 651-656. [CrossRef]

37. Haroonabadi, L.; Dashti, A.; Najipour, M. Investigation of the effect of thermal aging on rapid gas decompression (RGD) resistance of nitrile rubber. Polym. Test. 2018, 67, 37-45. [CrossRef]

38. Koopman, E.A.; Lowe, C.P. Advantages of a Lower-Andersen Thermostat in Molecule Dynamics Simulations. J. Chem. Phys. 2006, 124, 137. [CrossRef]

39. Davoodi, J.; Ahmadi, M. Molecule Dynamics Simulation of Elastic Properties of CuPd Nanowire. Compos. Part B 2012, $43,10$. [CrossRef]

40. Kucukpinar, E.; Doruker, P. Molecular simulations of gas transport in nitrile rubber and styrene butadiene rubber. Polymer 2006, 47, 7835-7845. [CrossRef]

41. Kucukpinar, E.; Doruker, P. Molecular simulations of small gas diffusion and solubility in copolymers of styrene. Polymer 2003, 44, 3607-3620. [CrossRef]

42. Zhu, L.; Zhao, S.; Zhang, C.; Cheng, X.; Hao, J.; Shao, X.; Zhou, C. Effects of chain structure on damping property and local dynamics of phenyl silicone rubber: Insights from experiment and molecular simulation. Polym. Test. 2021, 93, 106885. [CrossRef]

43. Zhu, L.; Chen, X.; Shi, R.; Zhang, H.; Han, R.; Cheng, X.; Zhou, C. Tetraphenylphenyl-modified damping additives for silicone rubber: Experimental and molecular simulation investigation. Mater. Design 2021, 202, 109551. [CrossRef]

44. Tan, J.H.; Chen, C.L.; Liu, Y.W.; Wu, J.Y.; Wu, D.; Zhang, H.L. Molecular simulations of gas transport in hydrogenated nitrile butadiene rubber. J. Polym. Res. 2020, 27, 1-10. [CrossRef]

45. Coleman, M.; Serman, C.; Bhagwagar, D.; Painter, P. A practical guide to polymer miscibility. Polymer 1990, 31, 1187-1203. [CrossRef] 